\title{
Prognostic significance of KLF4 expression in gastric cancer
}

\author{
ISAYA HASHIMOTO ${ }^{1}$, TAKUYA NAGATA ${ }^{1}$, SHINICHI SEKINE ${ }^{1}$, MAKOTO MORIYAMA ${ }^{1}$, \\ KAZUTO SHIBUYA ${ }^{1}$, SHOZO HOJO ${ }^{1}$, KOSHI MATSUI ${ }^{1}$, ISAKU YOSHIOKA ${ }^{1}$, TOMOYUKI OKUMURA ${ }^{1}$, \\ TAKASHI HORI $^{2}$, YUTAKA SHIMADA ${ }^{3}$ and KAZUHIRO TSUKADA ${ }^{1}$ \\ ${ }^{1}$ Department of Surgery and Science, Graduate School of Medicine and Pharmaceutical Sciences for Research; \\ ${ }^{2}$ Department of Pathology, Graduate School of Research into Medicine and Pharmaceutical Sciences, \\ University of Toyama, Toyama 930-0194; ${ }^{3}$ Department of Nanobio Drug Discovery, \\ Graduate School of Pharmaceutical Sciences, Kyoto University, Kyoto 606-8304, Japan
}

Received May 25, 2015; Accepted November 7, 2016

DOI: $10.3892 / 01.2016 .5499$

\begin{abstract}
To understand the roles of pluripotent stem cell-inducing genes in gastric cancer, the expression of Krüppel-like factor 4 (KLF4), Nanog, octamer-binding transcription factor 4 (Oct4), avian myelocytomatosis viral oncogene homolog (c-Myc) and sex-determining region Y-box 2 (SOX2) was examined using the newly developed gastric carcinoma tissue microarray. The associations between the immunohistochemical expression levels of the pluripotency-inducing factors and the clinicopathological data of 108 patients with gastric cancer were analyzed. No associations were identified between the expression levels of the five pluripotency-inducing factors and the tumor-node-metastasis (TNM) classification or clinicopathological characteristics of the patients. In addition, multivariate analysis revealed no association of Nanog, Oct4, SOX2 or c-Myc with the prognosis of the gastric cancer patients; however, low expression of KLF4 was determined to be an independent negative prognostic factor $(\mathrm{P}=0.0331)$, particularly in patients who underwent $\mathrm{R} 0$ resection (TNM stages 2 and 3; P=0.0048). In summary, low KLF4 expression was found to be negatively associated with overall survival, and may therefore be a useful prognostic marker in gastric cancer patients.
\end{abstract}

\section{Introduction}

Gastric cancer is a malignant tumor with a poor prognosis, and the various treatments available at present, including surgery, chemotherapy and radiotherapy, remain

Correspondence to: Dr Isaya Hashimoto, Department of Surgery and Science, Graduate School of Medicine and Pharmaceutical Sciences for Research, University of Toyama, 2630 Sugitani, Toyama 930-0194, Japan

E-mail: isaya138@med.u-toyama.ac.jp

Key words: gastric cancer, pluripotency-inducing factor, Krüppel-like factor 4 unsatisfactory (1). Development of gastric cancer is associated with a number of molecular abnormalities, the majority of which affect the downstream signal transduction pathways involved in cell growth and differentiation $(2,3)$. Investigation into such molecules is expected to provide useful prognostic biomarkers of gastric cancer that will aid in determining the treatment plan for individual patients. For example, methylation of the XIAP-associated factor 1 promoter (4),

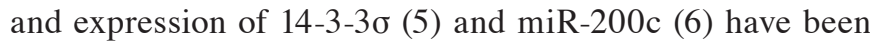
reported to be important for the prediction of poor prognosis in gastric cancer patients; however, further investigation is required.

Induced pluripotent stem (iPS) cells are cells that have acquired pluripotency following the introduction of various factors; octamer-binding transcription factor (Oct)3/4 and sex-determining region Y-box 2 (SOX2) plus Krüppel-like factor 4 (KLF4) and avian myelocytomatosis viral oncogene homolog (c-Myc), or Nanog and LIN28 have been shown to induce pluripotency in various murine and human cells (e.g., fibroblasts) $(7,8)$. These pluripotency-inducing factors have been detected in embryonic stem cells, as well as in normal cells and cancer cells, including gastric cancer (9). Although these factors are necessary in order for stem cells to acquire pluripotency, it has been suggested that they may have oncogenic potential in normal cells (10).

Expression of SOX2 has been reported to be important for tumorigenicity and chemoresistance (11). However, the inhibition of gastric cancer cell growth and the induction of apoptosis by SOX2 has also been reported (12); thus, the precise role of SOX2 remains to be clarified. Similarly, the transcription factor KLF4 has also been reported to be associated with tumor suppression as well as oncogenesis (13). KLF4 has been detected in cancer cells in gastric cancer (14), and has been proposed to be a useful biomarker; however, its exact role in gastric cancer cells remains unclear.

In the present study, the expression of five pluripotency-inducing factors in human gastric cancer specimens were investigated by immunohistochemistry and analyzed with respect to clinicopathological characteristics, revealing that decreased KLF4 expression was associated with poor prognosis in these patients. These data indicate that KLF4 
may be useful a molecular marker for poor prognosis in gastric cancer.

\section{Materials and methods}

Patients. Out of 130 consecutive primary gastric cancer patients who underwent surgery at the Department of Surgery and Science, Graduate school of Medicine and Pharmaceutical Sciences for Research, University of Toyama (Toyama, Japan) between January 2001 and June 2006, 108 cases were evaluated. A total of 22 cases were excluded in which the expression of the markers (C-Myc, Sox2, Nanog, KLF4 and Oct4) could not be evaluated due to peeling of the specimen from the slide. The depth of tumor invasion, the extent of lymph node metastasis and lymphovascular and vascular invasion, and the histological types were classified by the pathologists of Toyama University Hospital. The final pathological stage was confirmed according to the Union for International Cancer Control (UICC) classification system (15). The study protocol was approved by the Ethics Committee of the University of Toyama.

Construction of tissue microarray blocks. The expression of KLF4, Nanog, Oct4, SOX2 and c-MYC were investigated using a tissue microarray (TMA1150) created from resected gastric cancer specimens at Toyama University Hospital. Tumor areas with matched hematoxylin- and eosin-stained slides were selected and marked directly on the donor block. A cylindrical tissue sample (diameter, $0.6 \mathrm{~mm}$ ) was cored from the selected region in the donor block and inserted directly into the recipient block. A total of 108 gastric cancer tissues were included in the array block. Multiple 4- $\mu \mathrm{m}$ sections were cut with a microtome and transferred to Superfrost Plus glass slides (Thermo Fisher Scientific, Inc., Waltham, MA, USA).

Antibodies. The primary antibodies used in immunohistochemical staining were as follows: Anti-c-Myc $\left(\mathrm{IgG}_{1}\right.$ mouse monoclonal antibody; clone 9E10; \#sc-40; Santa Cruz Biotechnology, Inc., Santa Cruz, CA, USA); anti-KLF4 (IgG rabbit polyclonal antibody; \#ab34814; Abcam, Cambridge, UK); anti-Nanog (IgG rabbit polyclonal antibody; \#IHC-00205; Bethyl Laboratories, Inc., Montgomery, TX, USA); anti-Oct4 (IgG rabbit polyclonal antibody; \#ab19857; Abcam); and anti-SOX2 (IgG rabbit polyclonal antibody; \#AB5603; EMD Millipore, Billerica, MA, USA).

Immunohistochemical staining. Slides were incubated for 60 min with the primary antibodies at an optimized titer, diluted using Universal Blocking Reagent (BioGenex, Fremont, CA, USA). The antibodies were used at the following dilutions: KLF4, 1:100; Oct4, 1:100; Sox 2, 1:3,200; C-Myc, 1:50; and Nanog, 1:500, and incubated at room temperature for $30 \mathrm{~min}$. Following three washes in PBS, each series of sections was incubated for $30 \mathrm{~min}$ at room temperature with anti-mouse IgG1 goat polyclonal antibody (\#A90-105B; Bethyl Laboratories, Inc.) and anti-rabbit IgG-Fc fragment goat polyclonal antibody (\#A120-111B; Bethyl Laboratories, Inc.). diluted 1:250 in Universal Blocking Reagent. Following a further three washes in PBS, the slides were incubated for 45 min with avidin-biotin complex reagent (Vectastain Elite
Table I. Patient characteristics (all cases, $\mathrm{n}=108$ ).

\begin{tabular}{|c|c|c|}
\hline Characteristic & Value & $\%$ \\
\hline \multicolumn{3}{|l|}{ Age (years) } \\
\hline Median & 70 & - \\
\hline Range & $44-86$ & - \\
\hline \multicolumn{3}{|l|}{ Gender, $\mathrm{n}$} \\
\hline Male & 77 & 71.3 \\
\hline Female & 31 & 28.7 \\
\hline \multicolumn{3}{|l|}{ Tumor invasion, $\mathrm{n}$} \\
\hline $\mathrm{T} 1$ & 8 & 7.4 \\
\hline $\mathrm{T} 2$ & 19 & 17.6 \\
\hline $\mathrm{T} 3$ & 31 & 28.7 \\
\hline $\mathrm{T} 4$ & 50 & 46.3 \\
\hline \multicolumn{3}{|c|}{ Lymph node metastasis, $\mathrm{n}$} \\
\hline Positive & 78 & 72.2 \\
\hline Negative & 30 & 27.8 \\
\hline \multicolumn{3}{|c|}{ Lymphovascular invasion, $\mathrm{n}$} \\
\hline Positive & 92 & 85.2 \\
\hline Negative & 16 & 14.8 \\
\hline \multicolumn{3}{|l|}{ Vascular invasion, $\mathrm{n}$} \\
\hline Positive & 79 & 73.1 \\
\hline Negative & 29 & 26.9 \\
\hline \multicolumn{3}{|l|}{ Histology, n } \\
\hline Intestinal & 48 & 44.4 \\
\hline Diffuse & 60 & 55.6 \\
\hline \multicolumn{3}{|c|}{ Preoperative chemotherapy, $\mathrm{n}$} \\
\hline Administered & 19 & 17.6 \\
\hline Not administered & 89 & 82.4 \\
\hline \multicolumn{3}{|c|}{ Postoperative chemotherapy, $\mathrm{n}$} \\
\hline Administered & 61 & 56.5 \\
\hline Not administered & 47 & 43.5 \\
\hline \multicolumn{3}{|l|}{ UICC stage, $\mathrm{n}$} \\
\hline $\mathrm{I}$ & 29 & 26.9 \\
\hline II & 31 & 28.7 \\
\hline III & 17 & 15.7 \\
\hline IV & 31 & 28.7 \\
\hline
\end{tabular}

UICC, Union for International Cancer Control.

ABC kit; Vector Laboratories, Inc.) at room temperature. The reaction products were rinsed twice with $\mathrm{PBS}$, placed in $0.05 \mathrm{M}$ Tris- $\mathrm{HCl}$ buffer ( $\mathrm{pH} 7.5$ ) for $5 \mathrm{~min}$, and then developed in liquid 3,3-diaminobenzidine (Dako, Glostrup, Denmark) for $3 \mathrm{~min}$. Following the development, sections were washed twice with distilled water, lightly counterstained with Mayer's hematoxylin, dehydrated, cleared, and mounted with resinous mounting medium. All procedures were conducted at room temperature.

Pathological and immunohistochemical analysis. Two pathologists investigated the Tumor-Node-Metastasis (TNM) classification, according to the American Joint Committee 


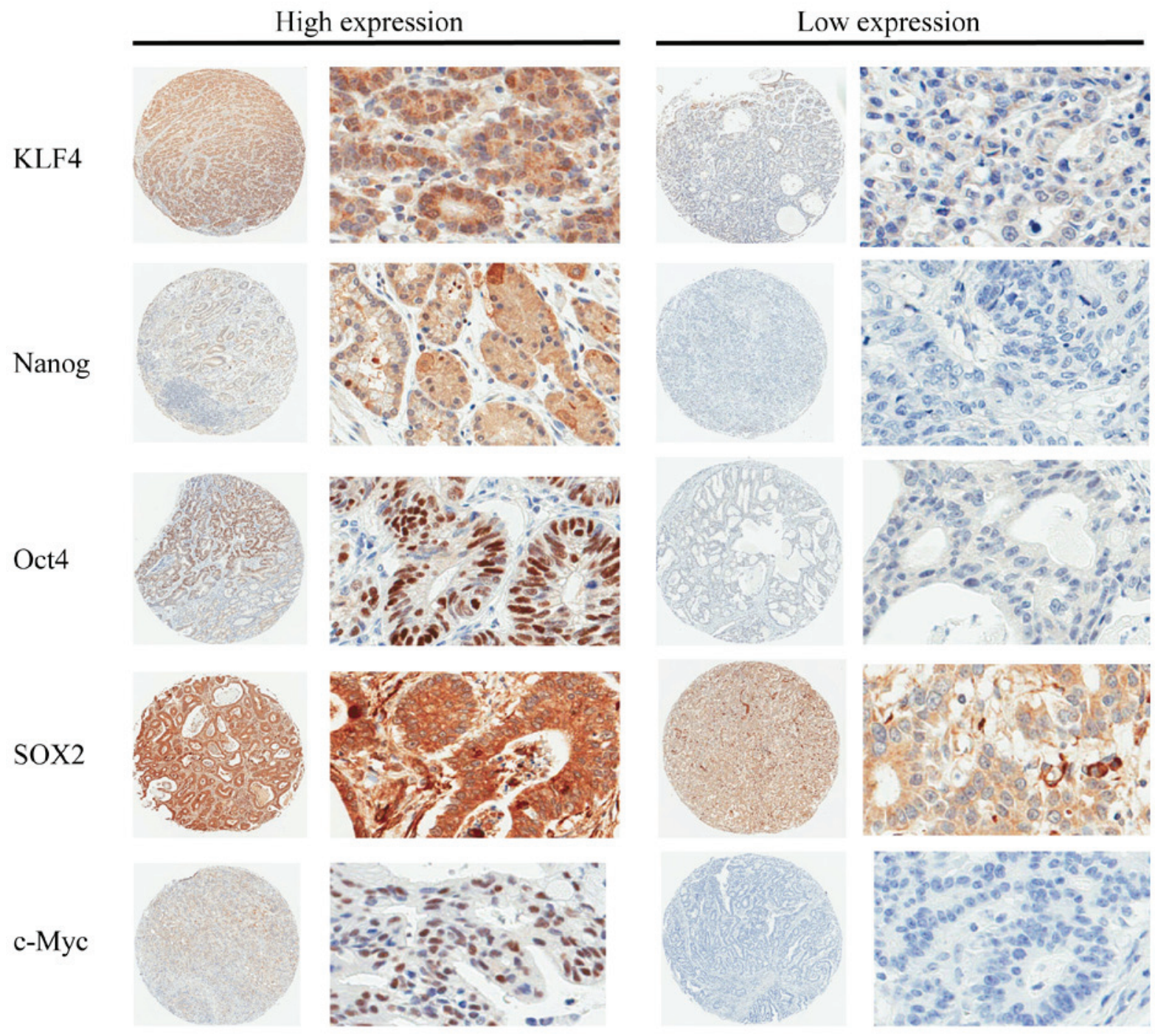

Figure 1. Immunohistochemical analysis of pluripotency-inducing factors in human gastric cancers. Immunohistochemistry was performed using antibodies against KLF4, Nanog, Oct4, SOX2 and c-Myc on tissue microarray slides. Representative slides are shown (circular images, x40 magnification; rectangular images, x400 magnification). KLF4, Krüppel-like factor 4; Oct4, octamer-binding transcription factor 4; SOX2, sex-determining region Y-box 2; c-Myc, avian myelocytomatosis viral oncogene homolog.

on Cancer (AJCC)/UICC criteria (16), for each patient who underwent surgery for the treatment of gastric cancer. The pathologist also analyzed the expression of each gene independently, and scored the intensity of expression [0 (no expression), 1 (weak expression), 2 (moderate expression) or 3 (strong expression)] as well as the distribution of expression $[0$ (no staining), 1 (1-50\% of tumor cells stained), or 2 (50-100\% of tumor cells stained)]. On the basis of the total score (the sum of the intensity and distribution scores), each patient was classified into one of two groups: The low expression group (total score, $0-2)$ or the high expression group (total score, $3-5)(17,18)$.

Statistical methods. The $\chi^{2}$ test was used to compare clinicopathological data. The overall survival (OS) rate following surgery was estimated for each group using the Kaplan-Meier method, and differences were assessed by the log-rank test and Wilcoxon test. $\mathrm{P}<0.05$ was considered to indicate statistical significance. All analyses were performed with JMP 11.0 software (SAS Institute, Inc., Cary, NC, USA).

\section{Results}

Patient characteristics. The clinical characteristics of the 108 gastric cancer patients are summarized in Table I. The median age of the patients was 70 years (range, 44-86 years), and the number of males $(\mathrm{n}=77 ; 71.3 \%)$ was more than twice that of the females $(n=31 ; 28.7 \%)$. Tumor invasion of pT3 or above was present in 81 patients (75.0\%), including 50 cases with pT4. Lymph node metastasis was identified in $72.2 \%$ of the patients. Lymphovascular and vascular invasion were present in 85.2 and $73.1 \%$ of patients, respectively. Advanced gastric cancer (stage II or higher) was present in 79 patients (73.1\%). Chemotherapy was administered preoperatively to 19 patients (17.6\%) and postoperatively to 61 patients (56.5\%), and 21 (34.4\%) of those that received postoperative chemotherapy relapsed. During the post-surgical follow-up period, relapse of gastric cancer occurred in 72 patients (66.7\%), of which 64 patients (88.9\% of relapses) succumbed to the disease. Factors involved in relapse were as follows: Peritoneal metastasis (34 patients), local recurrence (1 patient), liver 

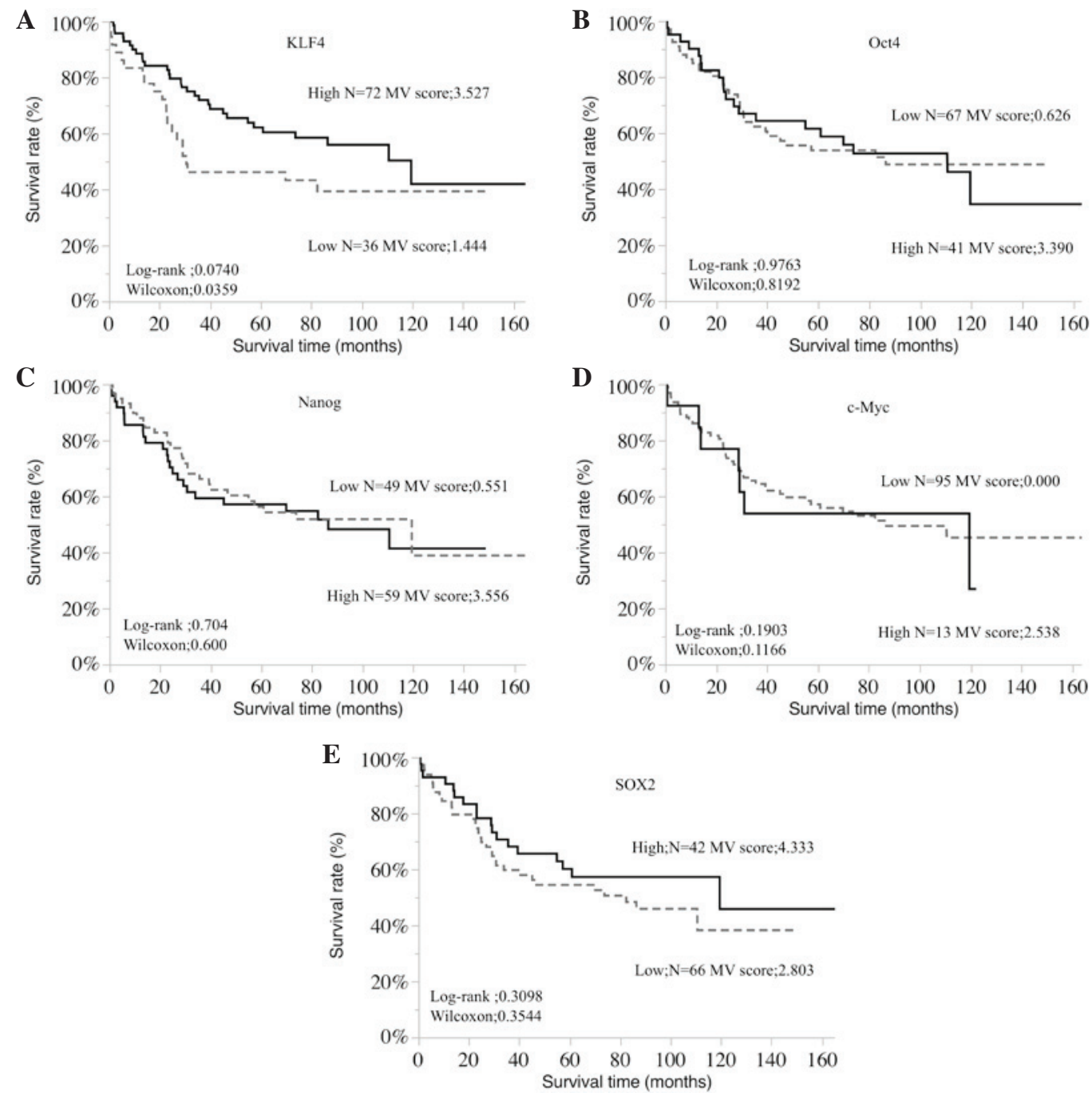

Figure 2. Overall survival rates of gastric cancer patients according to the expression of (A) KLF4, (B) Oct4, (C) Nanog, (D) c-Myc and (E) SOX2. Kaplan-Meier analysis revealed a significantly less favorable overall survival rate in patients with low KLF4 expression compared with those with high expression (log-rank, $\mathrm{P}=0.0740$; Wilcoxon, $\mathrm{P}=0.0359)$. MV, mean value of immunohistochemistry scores. KLF4, Krüppel-like factor 4; Oct4, octamer-binding transcription factor 4; c-Myc, avian myelocytomatosis viral oncogene homolog; SOX2, sex-determining region Y-box 2.

metastasis ( 5 patients), bone metastasis (2 patients), lymph node metastasis (10 patients) and brain metastasis (1 patient). The median post-surgical follow-up period was 56 months (range, 1-165 months).

Expression of pluripotency-inducing factors. The expression levels of KLF4, Nanog, Oct4, SOX2 and c-Myc were analyzed in tissue specimens from the 108 patients. Representative stained samples from the high and low expression groups for each factor are shown in Fig. 1. Following incubation with the anti-Nanog, anti-Oct4, and anti-c-Myc antibodies, staining was predominantly observed in the nuclei, while a lower rate of cytoplasmic staining was also visible. Nuclear and cytoplasmic staining were present to the same degree following immunohistochemical staining with anti-KLF4 and anti-SOX2 antibodies. The cell membranes in the gastric cancer specimens were not stained in this immunohistochemical analysis. Among the 108 cases, the overall ratios of patients in the high:low expression groups for each factor were as follows: KLF4, 72:36; Nanog, 59:49; OCT4, 41:67; SOX2, 42:66; and c-Myc, 13:95. Furthermore, the mean immunohistochemistry

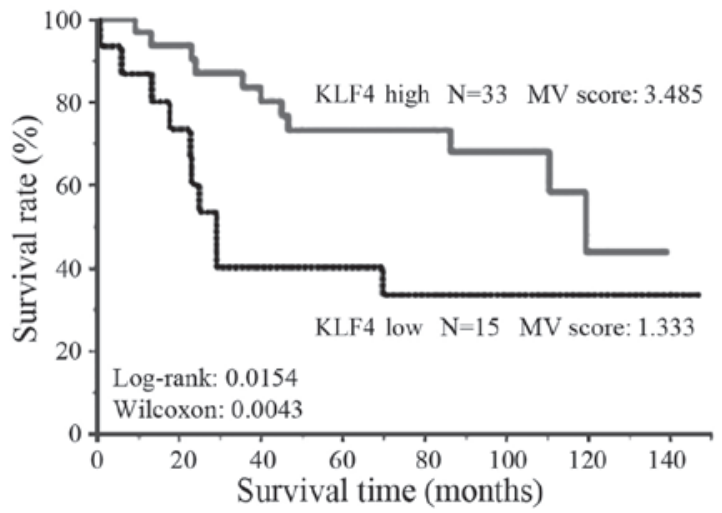

Figure 3. Survival rates of patients with stage II-III gastric cancer. Kaplan-Meier analysis revealed a significantly less favorable overall survival rate in patients with low KLF4 expression compared with those with high expression (log rank, 0.0154; Wilcoxon, $\mathrm{P}=0.0042$ ). KLF4, Krüppel-like factor 4.

scores (high:low expression group) for each factor were as follows: KLF4, 3.527:1.444; Nanog, 3.556:0.551; OCT4, 3.390:0.026; SOX2, 4.333:2.803; and c-Myc, 2.538:0.00. 
Table II. Association between patient characteristics and KLF4 expression in gastric cancer of various stages.

\begin{tabular}{|c|c|c|c|c|c|c|}
\hline \multirow[b]{3}{*}{ Variable } & \multicolumn{3}{|c|}{ All stages } & \multicolumn{3}{|c|}{ Stage II-III } \\
\hline & \multicolumn{2}{|c|}{ KLF4 expression } & \multirow[b]{2}{*}{ P-value } & \multicolumn{2}{|c|}{ KLF4 expression } & \multirow[b]{2}{*}{ P-value } \\
\hline & Low $(n=36)$ & $\operatorname{High}(\mathrm{n}=72)$ & & Low $(n=15)$ & $\operatorname{High}(n=33)$ & \\
\hline Age (years), median & 69 & 70 & 0.76 & 70 & 69 & 0.76 \\
\hline Gender, $\mathrm{n}$ & & & 0.75 & & & 0.36 \\
\hline Male & 25 & 57 & & 10 & 26 & \\
\hline Female & 11 & 15 & & 5 & 7 & \\
\hline Tumor invasion, $\mathrm{n}$ & & & 0.27 & & & 0.27 \\
\hline$\leq \mathrm{T} 2$ & 20 & 35 & & 13 & 28 & \\
\hline$>\mathrm{T} 2$ & 16 & 37 & & 2 & 5 & \\
\hline LN metastasis, $\mathrm{n}$ & & & 0.65 & & & 0.21 \\
\hline Positive & 27 & 51 & & 14 & 26 & \\
\hline Negative & 9 & 21 & & 1 & 7 & \\
\hline Number of metastatic LNs, $n$ & & & 0.87 & & & 0.38 \\
\hline$<7$ & 26 & 53 & & 9 & 24 & \\
\hline$\geq 7$ & 10 & 19 & & 6 & 9 & \\
\hline M stage, $\mathrm{n}$ & & & 0.76 & & & - \\
\hline 0 & 25 & 52 & & - & - & \\
\hline 1 & 11 & 20 & & - & - & \\
\hline Lymphovascular invasion, $\mathrm{n}$ & & & 0.41 & & & 0.23 \\
\hline Positive & 22 & 38 & & 15 & 30 & \\
\hline Negative & 14 & 34 & & 0 & 3 & \\
\hline Vascular invasion, $\mathrm{n}$ & & & 0.54 & & & 0.29 \\
\hline Positive & 25 & 54 & & 13 & 24 & \\
\hline Negative & 11 & 18 & & 2 & 9 & \\
\hline Histology, $\mathrm{n}$ & & & 0.41 & & & 0.33 \\
\hline Intestinal & 22 & 38 & & 10 & 17 & \\
\hline Diffuse & 14 & 34 & & 5 & 16 & \\
\hline \multicolumn{7}{|l|}{ Tumor size $(\mathrm{cm})$} \\
\hline Median & 5.0 & 5.6 & $0.43^{\mathrm{a}}$ & 6.0 & 5.0 & $0.35^{\mathrm{a}}$ \\
\hline$<5, \mathrm{n}$ & 15 & 27 & & 7 & 14 & \\
\hline$\geq 5, \mathrm{n}$ & 21 & 45 & $0.67^{\mathrm{b}}$ & 8 & 19 & $0.78^{\mathrm{b}}$ \\
\hline Preoperative chemotherapy, $\mathrm{n}$ & & & 0.37 & & & 0.5 \\
\hline Administered & 8 & 11 & & 4 & 6 & \\
\hline Not administered & 28 & 61 & & 11 & 27 & \\
\hline Postoperative chemotherapy, $\mathrm{n}$ & & & 0.33 & & & 0.28 \\
\hline Administered & 18 & 43 & & 10 & 27 & \\
\hline Not administered & 18 & 29 & & 5 & 6 & \\
\hline
\end{tabular}

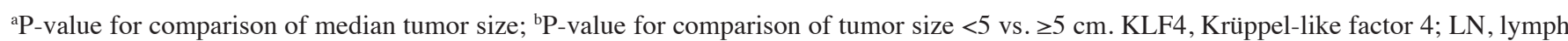
node; $\mathrm{M}$ stage, metastasis stage.

The expression level of KLF4 was also analyzed in the group of 48 patients who underwent $\mathrm{R} 0$ resection for stage II-III gastric cancer. High KLF4 expression was observed in 33 cases, while the remaining 15 cases exhibited low expression. These data indicate that the expression level of KLF4 was not significantly altered as the cancer stage increased.
Survival. The associations between the expression of each pluripotency-inducing factor and OS rate were assessed in all 108 patients (Fig. 2) and in the stage II-III patients who underwent R0 resection (Fig. 3). The results indicated that high expression KLF4 was significantly associated with a more favorable $\mathrm{OS}$ rate $(\mathrm{P}=0.0359)$; this difference in prognosis became more pronounced in the stage II-III cases $(\mathrm{P}=0.0042)$. 
Table III. Univariate (log-rank) and multivariate (Cox proportional hazards) analyses of the association between patient characteristics and prognosis in gastric cancer.

\begin{tabular}{|c|c|c|c|c|}
\hline \multirow[b]{2}{*}{ Factor } & \multirow{2}{*}{$\frac{\text { Univariate }}{\text { P-value }}$} & \multicolumn{3}{|c|}{ Multivariate } \\
\hline & & Risk ratio & $95 \% \mathrm{CI}$ & P-value \\
\hline Gender (male vs. female) & 0.157 & 1.58 & $0.768-1.928$ & 0.426 \\
\hline Age ( $\geq 70$ vs. $<70$ years $)$ & 0.135 & 1.20 & $0.917-2.803$ & 0.100 \\
\hline Tumor invasion ( $\geq \mathrm{T} 3$ vs. $<\mathrm{T} 3)$ & $<0.001^{\mathrm{a}}$ & 1.83 & $1.159-2.892$ & $0.007^{\mathrm{a}}$ \\
\hline Number of metastatic LNs ( $\geq 7$ vs. $<7$ ) & $<0.001^{\mathrm{a}}$ & 1.28 & $0.754-2.211$ & 0.358 \\
\hline M stage (1 vs. 0 ) & $<0.001^{\mathrm{a}}$ & 1.98 & $1.143-3.366$ & $0.015^{\mathrm{a}}$ \\
\hline Lymphovascular invasion (+ vs. -) & $<0.001^{\mathrm{a}}$ & 1.82 & $1.127-2.935$ & $0.010^{\mathrm{a}}$ \\
\hline Vascular invasion (+ vs. -) & $0.026^{\mathrm{a}}$ & 1.33 & $0.858-2.056$ & 0.200 \\
\hline Tumor size ( $\geq 5$ vs. $<5 \mathrm{~cm})$ & $0.029^{\mathrm{a}}$ & 1.16 & $0.738-1.855$ & 0.507 \\
\hline KLF4 expression (low vs. high) & $0.036^{\mathrm{a}}$ & 2.04 & $1.118-3.682$ & $0.033^{\mathrm{a}}$ \\
\hline Nanog expression (low vs. high) & 0.600 & - & - & - \\
\hline Oct4 expression (high vs. low) & 0.819 & - & - & - \\
\hline SOX2 expression (high vs. low) & 0.354 & - & - & - \\
\hline c-Myc expression (high vs. low) & 0.896 & - & - & - \\
\hline
\end{tabular}

\section{B, Stage II-III}

\begin{tabular}{|c|c|c|c|c|}
\hline \multirow[b]{2}{*}{ Factor } & \multirow{2}{*}{$\frac{\text { Univariate }}{\text { P-value }}$} & \multicolumn{3}{|c|}{ Multivariate } \\
\hline & & Risk ratio & $95 \% \mathrm{CI}$ & P-value \\
\hline Gender (male vs. female) & 0.103 & 4.68 & $1.143-32.195$ & $0.030^{\mathrm{a}}$ \\
\hline Age $(\geq 70$ vs. $<70$ years $)$ & 0.175 & 1.91 & $0.607-5.512$ & 0.256 \\
\hline Tumor invasion ( $\geq \mathrm{T} 3$ vs. $<\mathrm{T} 3)$ & $0.027^{\mathrm{a}}$ & 1.93 & $0.740-5.162$ & 0.176 \\
\hline Lymphovascular invasion (+ vs. -) & $<0.001^{\mathrm{a}}$ & 4.52 & $1.178-22.472$ & $0.027^{\mathrm{a}}$ \\
\hline Vascular invasion (+ vs. -) & $0.010^{\mathrm{a}}$ & 3.42 & $0.792-13.944$ & 0.096 \\
\hline Number of metastatic LNs ( $\geq 7$ vs. $<7$ ) & $0.001^{\mathrm{a}}$ & 1.12 & $0.342-3.379$ & 0.854 \\
\hline KLF4 expression (low vs. high) & $0.004^{\mathrm{a}}$ & 4.39 & $1.578-12.808$ & $0.005^{\mathrm{a}}$ \\
\hline
\end{tabular}

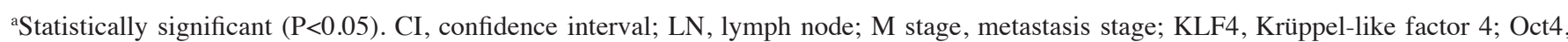
octamer-binding transcription factor 4; SOX2, sex-determining region Y-box 2; c-Myc, avian myelocytomatosis viral oncogene homolog.

No significant associations were identified between the other pluripotency-inducing factors and OS rate.

Associations between KLF4 and clinicopathological factors. Table II shows the correlations between the expression of KLF4 and the clinicopathological characteristics of gastric cancer patients. Patient age and gender, tumor invasion, number of metastatic lymph nodes, lymphovascular and vascular invasion, histology, stage, preoperative chemotherapy and postoperative chemotherapy were analyzed, revealing no correlations with the KLF4 expression. Similarly, in patients of stage II-III $(n=48)$ who underwent R0 resection, the same clinicopathological variables were not identified to be significantly associated with the expression of KLF4 (Table II).

Prognostic relevance of KLF4 expression. The associations of various clinicopathological factors with the prognosis of gastric cancer patients (all cases, $n=108$ ) are shown in Table IIIA. According to the results of the log-rank univariate analysis, the negative prognostic factors included tumor invasion $\geq \mathrm{T} 3(\mathrm{P}<0.001)$, positive lymphovascular invasion $(\mathrm{P}<0.001)$ and vascular invasion $(\mathrm{P}=0.0256), \geq 7$ metastatic lymph nodes $(\mathrm{P}=0.0012)$, tumor size $\geq 5 \mathrm{~cm}(\mathrm{P}=0.0287)$, and low expression of KLF4 $(\mathrm{P}=0.0359)$. The multivariate Cox proportional hazards analysis also revealed that low expression of KLF4 was an independent poor prognostic factor $(\mathrm{P}=0.0331)$.

In the patients with stage II-III gastric cancer $(n=48)$ who underwent $\mathrm{R} 0$ resection, the results of the log-rank univariate analysis revealed that the poor prognostic factors included tumor invasion $\geq \mathrm{T} 3(\mathrm{P}=0.0271)$, positive lymphovascular invasion $(\mathrm{P}<0.001)$ and vascular invasion $(\mathrm{P}=0.0098)$, $\geq 7$ metastatic lymph nodes $(\mathrm{P}=0.0014)$, and low expression of KLF4 $(\mathrm{P}=0.0042)$. Furthermore, the Cox's proportional 
hazards analysis revealed that low expression of KLF4 was an independent poor prognostic factor $(\mathrm{P}=0.0048)$ (Table IIIB).

\section{Discussion}

KLF4 is a zinc-finger transcription factor that is highly expressed in post-mitotic and terminally differentiated epithelial tissues, including those of the gastrointestinal tract, skin and lungs $(19,20)$. In the present study, KLF4 was found to be expressed in the cytoplasm and nuclei of gastric cancer cells, and its decreased expression was associated with a poor prognosis. It has been proposed that the regulation of KLF4 expression is involved in transcriptional and post-transcriptional regulation in gastric cancer (21). Liu et al (22) reported that KLF4 was predominantly expressed in the cytoplasm, rather than the nuclei, of nasopharyngeal carcinoma cells, and that the decreased expression of KLF4 in the cytoplasm was associated with poor prognosis in these cancer patients. Chen et al (23) reported that KLF4 existed predominantly in the nuclei of oral cancer cells, and also that the loss of KLF4 in the nuclei was associated with poor prognosis. These reports suggest that the localization of KLF4 may differ between organs or according to the role of KLF4; however, it is notable that the decrease in KLF4 was associated with the progression of the cancer.

With regard to the presence of KLF4 in tumor cells, various studies have revealed decreased KLF4 expression in patients with nasopharyngeal (22), colorectal (24), renal (25), lung (26), cervical (27) and breast cancer (28) who had poor prognosis. Based on these results, KLF4 was suggested to function as a tumor suppressor. Accordingly, the overexpression of KLF4 was demonstrated to inhibit cell growth, migration, invasion and metastasis in liver, lung and colorectal cancer (29-31), and induce tumor cell apoptosis in esophageal cancer (32) and bladder cancer (33). These functional investigations also suggested that the loss of KLF4 expression may be involved in the initiation and formation of precancerous lesions in various cancer types. Previous multivariate analyses revealed that decreased expression of KLF4 protein was a significant predictor of poor prognosis for patients with several cancer types regardless of the clinical stage $(30,34)$. Thus, KLF4 downregulation appears to be an independent prognostic factor in various types of malignant tumors.

Japanese gastric cancer treatment guidelines recommend that adjuvant chemotherapy is administered following the standard surgical treatment for patients with gastric cancer of stage II-III (35). The standard surgical treatment for gastric cancer in Japan is defined as the excision of more than two-thirds of the stomach and the dissection of lymph nodes up to the D2 area. This procedure is widely performed in Japan, with few prognostic differences between gastrectomy and D2 area lymph node dissection. In the present study, when the analysis was limited to patients with stage II-III gastric cancer, a more pronounced difference in prognosis according to KLF4 expression was observed, as compared with the analysis of all stages. Thus, it is hypothesized that the expression of KLF4 is an independent prognostic factor that is not affected by the progression of the tumor or the treatment methods.

Several reports have indicated that KLF4 is an important regulator of tumor cell proliferation. Wei et al (14) reported that increased expression of KLF4 induced cell cycle arrest and apoptosis in gastric cancer cells. Consistently, KLF4 has been shown to induce apoptosis in bladder cancer (33), colon cancer (36) and leukemia (37) cells. The mechanism of apoptosis induction by KLF4 has not been elucidated. In HT-29 human colon adenocarcinoma cells, KLF4 overexpression was revealed to significantly inhibit the mRNA expression of cyclin D1, as well as the activity of the cyclin D1 gene promoter, and induce cell cycle arrest at the G1/S boundary (38). These data indicate that KLF4 may function as a transcriptional repressor of cyclin D1 to regulate colon cell growth. Tiwari et al (39) reported that suppressing KLF4 in breast cancer cells induces mitogen-activated protein kinase 8-mediated epithelial-mesenchymal transition. KLF4 may therefore be involved in cancer metastasis.

In summary, the present study investigated the expression levels of five pluripotency-inducing factors (c-Myc, KLF4, Nanog, Oct4, and SOX2) in gastric cancer specimens, and the association between the expression of KLF4 and the prognosis of gastric cancer patients was also assessed, indicating that low KLF4 expression was an independent negative prognostic factor. It is suggested that KLF4 may exert a suppressive effect on the proliferation and metastasis of this type of cancer. Furthermore,the expression and activity of pluripotency-inducing factors in CSCs may be an important direction for cancer research in the future.

\section{Acknowledgements}

The authors are grateful to Dr Takashi Hori (Department of Pathology, University of Toyama) for providing valuable technical assistance. This study was supported by grants from the Ministry of Education, Culture, Sports, Science and Technology of Japan.

\section{References}

1. Catalano V, Labianca R, Beretta GD, Gatta G, de Braud F and Van Cutsem E: Gastric cancer. Crit Rev Oncol Hematol 71: 127-164, 2009.

2. Chan AO, Luk JM, Hui WM and Lam SK: Molecular biology of gastric carcinoma: From laboratory to bedside. J Gastroenterol Hepatol 14: 1150-1160, 1999.

3. Fenoglio-Preiser CM, Wang J, Stemmermann GN and Noffsinger A: TP53 and gastric carcinoma: A review. Hum Mutat 21: 258-270, 2003

4. Lin ZQ, Lv P, Lu XX, Yu JL, Han J, Ying LS, Zhu X, Zhu WY, Fang $\mathrm{XH}$, Wang $\mathrm{S}$ and Wu YC: Circulating methylated $X A F 1$ DNA indicates poor prognosis for gastric cancer. PLoS One 8: e67195, 2013

5. Li YL, LIU L, Xiao Y, Zeng T and Zeng C: 14-3-30 is an independent prognostic biomarker for gastric cancer and is associated with apoptosis and proliferation in gastric cancer. Oncol Lett 9: 290-294, 2015.

6. Valladares-Ayerbes M, Reboredo M, Medina-Villaamil V, Iglesias-Díaz P, Lorenzo-Patiño MJ, Haz M, Santamaria I, Blanco M, Fernández-Tajes J, Quindós M, et al: Circulating miR-200c as a diagnostic and prognostic biomarker for gastric cancer. J Transl Med 10: 186, 2012.

7. Takahashi K and Yamanaka S: Induction of pluripotent stem cells from mouse embryonic and adult fibroblast cultures by defined factors. Cell 126: 663-676, 2006.

8. Yu J, Vodyanik MA, Smuga-Otto K, Antosiewicz-Bourget J, Frane JL, Tian S, Nie J, Jonsdottir GA, Ruotti V, Stewart R, et al: Induced pluripotent stem cell lines derived from human somatic cells. Science 318: 1917-1920, 2007.

9. Li N, Deng W, Ma J, Wei B, Guo K, Shen W, Zhang Y and Luo S: Prognostic evaluation of Nanog, Oct4, Sox2, PCNA, Ki67 and E-cadherin expression in gastric cancer. Med Oncol 32: 433, 2015. 
10. Al-Marzoqee FY, Kholder G, Al-Awadhi H, John R, Beg A Vincze A, Branicki F and Karam SM: Upregulation and inhibition of the nuclear translocation of Oct4 during multistep gastric carcinogenesis. Int J Oncol 41: 1733-1743, 2012.

11. Tian T, Zhang Y, Wang S, Zhou J and Xu S: Sox 2 enhances the tumorigenicity and chemoresistance of cancer stem-like cells derived from gastric cancer. J Biomed Res 26: 336-345, 2012.

12. Otsubo T, Akiyama Y, Yanagihara K and Yuasa Y: SOX2 is frequently downregulated in gasyric cancers and and inhibits cell growth through cell-cycle arrest and apoptosis. Br J Cancer 98: 824-831, 2008.

13. Evans PM and Liu C: Roles of Krüpel-like factor 4 in normal homeostasis, cancer and stem cells. Acta Biochim Biophys Sin (Shanghai) 40: 554-564, 2008.

14. Wei D, Gong W, Kanai M, Schlunk C, Wang L, Yao JC, Wu TT, Huang S and Xie K: Drastic down-regulation of Krüppel-like factor 4 Expression is critical in human gastric cancer development and progression. Cancer Res 65: 2746-2754, 2005.

15. Sobin LH, Gospodarowicz MK and Wittekind C (eds): International Union Against Cancer (UICC) TNM Classification of Malignant Tumors. 7th edition. Wiley-Blackwell, New York, 2010.

16. McGhan LJ, Pockaj BA, Gray RJ, Bagaria SP and Wasif N: Validation of the updated 7 th edition AJCC TNM staging criteria for gastric adenocarcinoma. J Gastrointest Surg 16 53-61, 2012.

17. Fukuoka J, Fujii T, Shih JH, Dracheva T, Meerzaman D, Player A, Hong K, Settnek S, Gupta A, Buetow K, et al: Chromatin remodeling factors and BRM/BRG1 expression as prognostic indicators in non-small cell lung cancer. Clin Cancer Res 10: 4314-4324, 2004.

18. Sekine S, Shimada Y, Nagata T, Moriyama M, Omura T, Watanabe T, Hori R, Yoshioka I, Okumura T, Sawada S, et al: Prognostic significance of aquaporins in human biliary tract carcinoma. Oncol Rep 27: 1741-1747, 2012.

19. Garrett-Sinha LA, Eberspaecher H, Seldin MF and de Crombrugghe B: A gene for a novel zinc-finger protein expressed in differentiated epithelial cells and transiently in certain mesenchymal cells. J Biol Chem 271: 31384-31390, 1996.

20. Shields JM, Christy RJ and Yang VW: Identification and characterization of a gene encoding a gut-enriched Krüppel-like factor expressed during growth arrest. J Biol Chem 271: 20009-20017, 1996.

21. Neng Z Jun Z, Leiyuan S, Lang Z, Miao H, Zhen $H$ and Ziwei W: Krüppel-like factor 4 negatively regulates $\beta$-catenin expression and inhibits the proliferation, invasion and metastasis of gastric cancer. Int J Oncol 40: 2038-2048, 2012.

22. Liu Z, Yang H, Luo W, Jiang Q, Mai C, Chen Y, Zhen Y, Yu X, Long X and Fang W: Loss of cytoplasmic KLF4 expression is correlated with the progression and poor prognosis of nasopharyngeal carcinoma. Histopathology 63: 362-370, 2013.

23. Chen CJ, Hsu LS, Lin SH, Chen MK, Wang HK, Hsu JD, Lee $\mathrm{H}$ and Yeh KT: Loss of nuclear expression of Krüppel-like factor 4 is associated with poor prognosis in patients with oral cancer. Hum Pathol 43: 1119-1125, 2012.
24. Li J, Zheng H, Yu F, Yu T, Liu C, Huang S, Wang TC and Ai W: Deficiency of the Krüppel-like factor KLF4 correlates with increased cell proliferation and enhanced skin tumorigenesis. Carcinogenesis 33: 1239-1246, 2012

25. Liu Y, Zhang C, Fan J, Xiao L, Yin B, Zhou K and Xia S: Comprehensive analysis of clinical significance of stem-cell related factors in renal cell cancer. World J Surg Oncol 9: 121, 2011.

26. Hu W, Hofstetter WL, Li H, Zou Y, He Y, Pataer A, Wang L, Xie K, Swisher SG and Fang B: Putative tumor-suppressive function of Krüppel-like factor 4 in primary lung carcinoma. Clin Cancer Res 15: 5688-5695, 2009.

27. Yang WT and Zheng PS: Krüppel-like factor 4 functions as a tumor suppressor in cervical carcinoma. Cancer 118: 3691-3702, 2012.

28. Nagata T, Shimada Y, Sekine S, Hori R, Matsui K, Okumura T, Sawada S, Fukuoka J and Tsukada K: Prognostic significance of NANOG and KLF4 for breast cancer. Breast Cancer 21: 96-101, 2014.

29. Tiwari N, Meyer-Schaller N, Arnold P, Antoniadis H, Pachkov M, van Nimwegen E and Christofiri G: Klf4 is a transcriptional regulator of genes critical for EMT, including Jnk1 (Mapk8). PLoS One 8: e57329, 2013.

30. Zhou Y, Hofstetter WL, He Y, Hu W, Pataer A, Wang L, Wang J, Zhou Y, Yu L, Fang B and Swisher SG: KLF4 inhibition of lung cancer cell invasion by suppression of SPARC expression. Cancer Biol Ther 9: 507-513, 2010.

31. Leng Z, Tao K, Xia Q, Tan J, Yue Z, Chen J, Xi H, Li J and Zheng H: Krüppel-like factor 4 acts as an oncogene in colon cancer stem cell-enriched spheroid cells. PLoS One 8: e56082, 2013.

32. Yang Y, Goldstein BG, Chao HH and Katz JP: KLF4 and KLF5 regulate proliferation, apoptosis and invasion in esophageal cancer cells. Cancer Biol Ther 4: 1216-1221, 2005.

33. Ohnishi S, Ohnami S, Laub F, Aoki K, Suzuki K, Kanai Y, Haga K, Asaka M, Ramirez F and Yoshida T: Downregulation and growth inhibitory effect of epithelial-type Krüppel-like transcription factor KLF4, but not KLF5, in bladder cancer. Biochem Biophys Res Commun 308: 251-256, 2003.

34. Tang W, Zhu Y, Gao J, Fu J, Liu C, Liu Y, Song C, Zhu S, Leng Y, Wang G, et al: MicroRNA-29 promotes colorectal cancer metastasis by regulating matrix metalloproteinase 2 and E-cadherin via KLF4. Br J Cancer 110: 450-458, 2014.

35. Gastric Cancer treatment guidelines 2014, version 4. Kodera Y and Sano T (eds). Japanese Gastric Cancer Association, 2014.

36. Chen ZY, Shie J and Tsen C: Up-regulation of gut-enriched krüppel-like factor by interferon-gamma in human colon carcinoma cells. FEBS Lett 477: 67-72, 2000 .

37. Yasunaga J, Taniguchi Y, Nosaka K, Yoshida M, Satou Y, Sakai T, Mitsuya $\mathrm{H}$ and Matsuoka M: Identification of aberrantly methylated genes in association with adult T-cell leukemia. Cancer Res 64: 6002-6009, 2004.

38. Shie JL, Chen ZY, Fu M, Pestell RG and Tseng CC: Gut-enriched Krüppel-like factor represses cyclin D1 promoter activity through Spl motif. Nucleic Acids Res 28: 2969-2976, 2000.

39. Tiwari N, Meyer-Schaller N, Arnold P, Antoniadis H, Pachkov M, van Nimwegen E and Chritofori G: Klf4 is a transcriptional regulator of genes critical for EMT, including Jnk1 (Mapk8). PLoS One 8: e57329, 2013. 